\title{
DENDROCLIMATOLOGIA COM AMOSTRAS DE ARAUCARIA ANGUSTIFOLIA COLETADAS EM SANTA CATARINA
}

\section{DENDROCLIMATOLOGY WITH SAMPLES OF ARAUCARIA ANGUSTIFOLIA COLLECTED IN SANTA CATARINA}

\section{Caren Lorensi ${ }^{1}$ \\ Alan Prestes ${ }^{2}$}

\begin{abstract}
Resumo: Amostras do lenho de Araucaria angustifolia coletadas em Painel, no estado de Santa Catarina, foram analisadas em comparação com séries climatológicas locais, a fim de se conhecer a influência do clima no crescimento das árvores. Foram utilizadas séries de precipitação, temperatura e da evapotranspiração. O estudo aponta que as variáveis climatológicas influenciam no crescimento das árvores, porém atuam em conjunto, deixando claro que não são os valores extremos dessas variáveis que influenciam, mas sim o balanço entre elas que deixa o solo em condições favoráveis para o desenvolvimento dos vegetais. Na análise sazonal, ficou claro que o excesso de chuva pode ser prejudicial, porém, se atrelada a temperaturas mais elevadas, pode representar um auxílio no crescimento. $A$ evapotranspiração local segue a tendência da temperatura e nos regimes sazonais mostrou que a influência conjunta da precipitação e da temperatura define seu grau de influência no crescimento das plantas. Não se descarta a hipótese de que uma cronologia mais robusta e com maior alcance temporal poderia elencar mais características do local. Mesmo assim, os resultados apontam que as plantas desse sítio são sensíveis ao clima local e podem ser utilizadas como registros naturais.
\end{abstract}

Palavras-chave: Dendroclimatologia; séries temporais; pinheiro-do-Paraná.

Abstract: Samples of Araucaria angustifolia wood collected in Painel, in the state of Santa Catarina, were analyzed and compared to local climatological series in order to know the influence of climate on tree growth. Precipitation, temperature and evapotranspiration series were used. The study indicates that the climatological variables influence in the growth of the trees, but they act together, making it clear that it is not the extreme values of these variables that influence, but the balance among them that leaves the soil in favorable conditions for the development of the plants. The seasonal analysis shows soaked soil can be harmful to plants; however, in cases with higher temperatures it may be favorable for the growth. The local evapotranspiration follows the same trend of the temperature and in seasonal patterns the combined influence of precipitation and temperature can help in plant growth. Certainly, a longer chronology and with more samples could improve results and local features. Nevertheless, the results shown here indicate that the plants of this site are sensitive to the local climate and can be used as natural records.

Keywords: Dendroclimatology; time series; pinheiro-do-Paraná

\section{INTRODUÇÃO}

A Floresta Ombrófila Mista (FOM) estende-se pelos estados do sul brasileiro além de São Paulo e Minas Gerais (INOUE; RODERJAN; KUNIYOSHI, 1984). É também conhecida como Floresta de Araucária ou Pinheiral, devido à presença marcante do pinheiro-do-paraná ou Araucaria angustifolia (Bert.) O. Kuntze (GERHARDT et al., 2001) que corresponde a mais de $40 \%$ dos indivíduos arbóreos presentes. Devido ao porte,

\footnotetext{
1 Possui doutorado em doutorado em Física e Astronomia pela Universidade do Vale do Paraíba - UNIVAP, Brasil. E-mail: caren.lorensi@gmail.com.

2 Possui doutorado em Geofísica Espacial pelo Instituto Nacional de Pesquisas Espaciais - INPE, Brasil. E-mail: prestes@univap.br.
} 
ao grande número de indivíduos e às copas corimbiformes, essa árvore imprime um aspecto fitofisionômico próprio dessa formação (SONEGO; BACKES; SOUZA, 2007). A Araucária é a maior de todas as árvores florestais do sul do Brasil, e devido à sua grandiosidade e expressiva dominância, tornou-se símbolo do estado do Paraná (MAACK, 1968; LINDMANN, 1974).

Além da Araucaria angustifolia na FOM existem outras espécies como a erva-mate (Ilex paraguariensis A. St.-Hil.) e Imbuia (Ocotea porosa (Nees) Barroso), canelalageana (Ocotea pulchella (Nees) Mez) (PÉLLICO NETTO; SANQUETTA; BRENA, 2002; RODERJAN et al., 2002), espécies de grande valor econômico. E, pela intensa exploração comercial dessas espécies, a FOM encontra-se bastante fragmentada com poucos remanescentes que representem uma amostra adequada desse tipo de vegetação (NASCIMENTO; LONGHI; BRENA, 2001).

Investigações em anéis de crescimento de árvores ocorrem há muitos séculos. Conta-se que em 370 a.C. Theophrastus, em seu livro Pery phytön Historia, descreveu os anéis de crescimento nos troncos das árvores e afirmou que havia relação entre o crescimento desses anéis e o meio ambiente (COELHO, 2011).

Com o passar dos anos e com a melhoria de técnicas, o emprego de anéis de crescimento de árvores como registros naturais tornou-se uma ferramenta confiável para estudar o clima; pois, com registros naturais de boa qualidade, foi possível suprir a escassez de dados climáticos históricos, desenvolvendo-se o que conhecemos por dendroclimatologia (FRITTS, 1976).

Pesquisas em dendroclimatologia permitem avaliar perfis de precipitação, temperatura, assim como estudo de eventos climáticos como o El Niño Oscilação Sul entre outros. Obtendo-se a validação dos perfis climatológicos encontrados nas séries dendrocronológicas, estes podem ser utilizados como substitutos ou auxiliares aos registros instrumentais e até mesmo obter-se reconstruções do clima do passado. Para isso, Bryson e Dutton (1961), aconselham que antes é necessário estabelecer para qual variável climatológica a série de anéis de árvore é equivalente, assim como saber interpretar o comportamento dessa série.

Quando se trata de áreas vegetadas, é comum haver o monitoramento da evapotranspiração, que é a transferência de vapor d'água para a atmosfera. A evapotranspiração pode se tratar da evaporação da umidade existente (solo ou água) e também da transpiração resultante da atividade biológica dos seres vivos (VAREJÃOSILVA, 2005).

O presente trabalho objetiva investigar registros do clima de um sítio na serra catarinense por meio da análise dos anéis de crescimento de $A$. angustifolia. 


\section{MATERIAL E MÉTODOS}

\subsection{Caracterização do local de coleta}

O Sul do Brasil caracteriza-se por regimes homogênos de chuva e variações sazonais de temperatura bastante demarcadas. O município de Painel (27055'S e $50^{\circ} 06^{\prime}$ (), localizado na Região dos Campos de Lages, ao Sul Catarinense, é uma das regiões mais frias do Brasil, com episódios de geadas intensas e, em alguns invernos, ocorrência de neve (MONTEIRO, 2001). Com relação à precipitação, Santa Catarina é um dos Estados que apresenta melhor distribuição de precipitação pluviométrica durante o ano, devido aos diversos sistemas meteorológicos que atuam nos regimes de chuva (MONTEIRO, 2001).

Segundo a classificação de Köppen (KÖPPEN, 1931), o estado de Santa Catarina apresenta os climas do Grupo C - mesotérmico, com as temperaturas médias do mês mais frio abaixo de $18^{\circ} \mathrm{C}$ e superior a $3^{\circ} \mathrm{C}$. Pertence ao tipo (f), pois não possui estação seca definida e apresenta índices pluviométricos superiores a $60 \mathrm{~mm}$ mensais. Devido à altitude, há ocorrência de verão (a) quente no litoral e no oeste, cujas temperaturas médias são mais elevadas e de verão (b) fresco, nas zonas mais elevadas do planalto. Portanto, predominam no estado os climas: Cfa - Com verão quente e Cfb - com verão fresco. A cidade de Painel, que econtra-se na região serrada catariense, apresenta clima do tipo $\mathrm{Cfb}$, com verões amenos.

\subsection{Séries temporais}

Foram utilizadas séries temporais de precipitação e de temperatura média mensal de São Joaquim (aproximadamente a $52 \mathrm{~km}$ do sítio de coleta), por não haver séries climatológicas para Painel/SC. Essa mesma metodologia foi usada por Zanzi et al. (2007). As séries foram extraídas do banco de dados históricos do Instituto Nacional de Meteorologia (INMET).

Para as séries dendrocronológicas, utilizaram-se amostras do lenho de Araucaria angustifolia Bertol. O. Kuntze, uma conífera que ocorre ao longo do sul e do sudeste brasileiro, nordeste da Argentina e sudeste do Paraguai (OLIVEIRA, 2007). É uma árvore com grande potencial dendrocronológico, com anéis de crescimento muito nítidos e lenho inicial e tardio bastante demarcados (SANTAROSA et al., 2007).

A série dendrocronológica constriu-se a partir de 8 amostras coletadas de 4 indivíduos, pelo método não-destrutivo, com o uso da sonda de Pressler $(5 \mathrm{~mm})$ a, aproximadamente, 1,2 $\mathrm{m}$ acima do nível do solo. As coletas foram feitas em janeiro de 2013. Os cilindros coletados foram acomodados em suporte de madeira de modo que os anéis de crescimento estivessem no sentido longitudinal. O uso do suporte evita que a madeira envergue, preservando o lenho enquanto este é deixado para a secagem natural. 
Após a secagem, as amostras foram submetidas a processos de lixamento para remover imperfeições do lenho e de polimento para que seus anéis de crescimento ficassem visíveis. Para isso, foram usadas lixas de diferentes grânulos (80 a 500 grãos). Com as amostras lixadas e polidas, fez-se a medição dos anéis de crescimento com o uso da mesa de mensuração VELMEX, com deslocamento calibrado para precisão de $0,001 \mathrm{~mm}$. A datação dos anéis anuais de crescimento foi realizada no sentido cascamedula, tendo como referência a última formação completa do anel que correspondeu ao ano de 2011.

Com todas as baguetas já medidas e relacionadas ao ano do calendário civil, iniciou-se o processo para se obter a série cronológica para cada indivíduo. Para isso, fez-se a correlação entre as amostras extraídas de cada indivíduo, e, com aquelas que apresentaram o maior coeficiente, calculou-se a média (ENQUIST; LEFFLER, 2001), para a obtenção de uma série temporal para cada indivíduo. O processo de correlação entre as amostras também é aplicado como forma de selecionar as melhores amostras, pois aquelas que apresentaram baixa correlação foram descartadas, assim como as que apresentavam tendência de crescimento muito discrepante com relação ao grupo, análogo ao sugerido por Flower e Smith (2010).

Para que as tendências indesejáveis ao foco da pesquisa fossem eliminadas, foram aplicadas nas séries temporais de anéis de crescimento funções de ajuste. $O$ objetivo desse procedimento é obter a melhor curva que represente as tendências de longos períodos associadas ao ritmo de crescimento de cada série (FICHTLER et al., 2004). Esse processo chama-se padronização, na qual espera-se eliminar os sinais nãoclimáticos presentes nas séries dendrocronológicas (TROVATI; FERRAZ, 1984).

A padronização é efetuada com a divisão da série de anéis de crescimento (RT) pela função de ajuste (GT), conforme a Equação 1.

$$
I=\frac{R_{t}}{G_{t}} \quad \text { (Equação 1) }
$$

O resultado dessa divisão é o Índice (I).

As funções de ajuste utilizadas na padronização foram a linear e a polinomial de grau 3, selecionadas entre aquelas que apresentaram melhor correlação com a série dendrocronológica, conforme sugerido por Savva et al. (2002). Dessa forma, conseguiuse respeitar as particularidades de crescimento de cada amostra, assim como a persistência dos sinais climáticos. Com os índices, fez-se uma média para, então, obterse a cronologia local. Segundo Trovati e Ferraz (1984), a média entre as árvores oferece melhor relação com o clima, pois o sinal climático que influenciou no crescimento de todos os indivíduos se mantém quando a média é feita.

Após todos os tratamentos aplicados, obteve-se a cronologia do local cobrindo o 
intervalo de 1950-2010, composta por 6 amostras de 4 indivíduos.

Para analisar a influência das variáveis climatológicas nos anéis de crescimento das árvores, foi aplicada Correlação de Pearson para as séries de precipitação e temperatura média anual além da série de temperatura em escala sazonal. Para isso, considerou-se o ano T (ano corrente), respeitando o calendário fisiológico da planta, que inicia seu processo de crescimento em setembro e encerra em março (primavera/verão).

Esse procedimento visa conhecer padrões ou tendências no crescimento anual das plantas que podem ocorrer em determinados períodos do ano.

Consideraram-se significativas as correlações cujos coeficientes ficaram acima de $90 \%$ de confiança $(p<0,10)$.

\section{RESULTADOS}

A partir dos dados climatológicos mensais calculou-se a série de precipitação e temperatura média anual (Figura 1).

Figura 1 - Climatologia de São Joaquim/SC. Precipitação (barras) e temperatura (linha) a partir de valores mensais de 1961-2010.

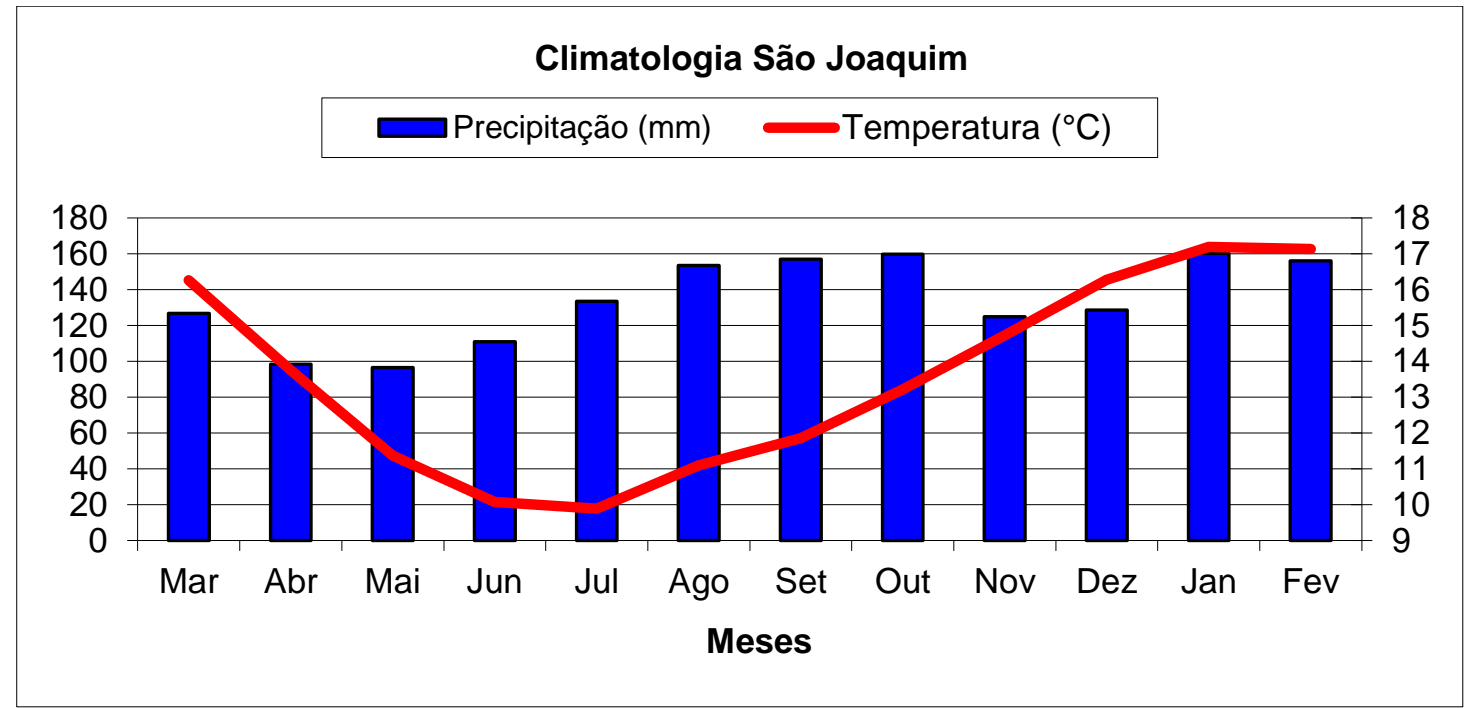

Fonte: Autores.

Pelo método de Thornthwaite (1948), construiu-se a série mensal de evapotranspiração para São Joaquim (Figura 2). 
Figura 2 - Série mensal de evapotranspiração de 1961-2010.

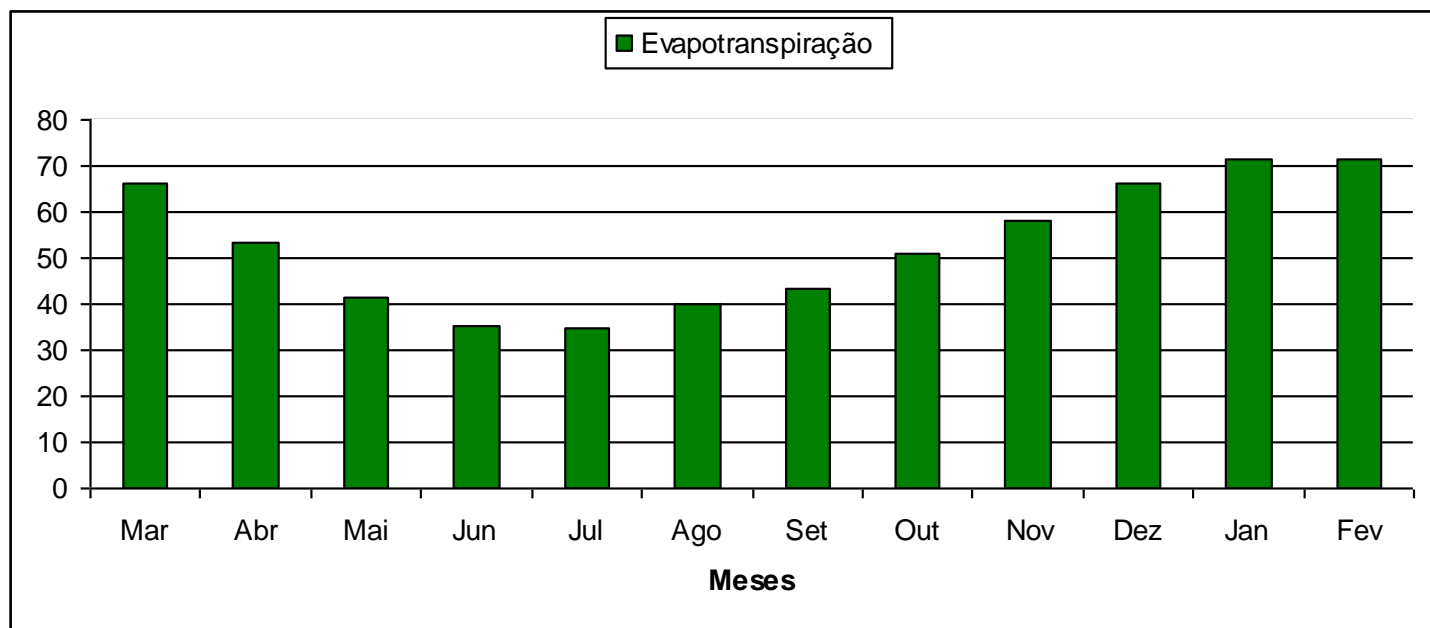

Fonte: Autores.

A série de evapotranspiração, pelo método de Thornthwaite, obtém-se por meio da Equação 2:

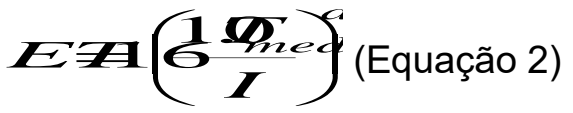

Porém, antes tem-se que conhecer os valores de:

$$
\begin{gathered}
I=\sum_{1}^{12} i(\text { Equação 3) } \\
i=\left(\frac{\text { Tmed }_{\text {e }}}{5}\right)^{1,51}(\text { Equação 4) }
\end{gathered}
$$

Em que:

I é o índice de calor anual, i é o índice de calor mensal, Tmed é a temperatura média mensal. Obtendo-se esses valores, é preciso calcular o coeficiente "a", que está baseado em I:

$$
a=6.75 \times 10^{-7} \times I^{3}-7,71 \times 10^{-5} \times I^{2}+0.01791 \times I+0,49239 \text { (Equação 5) }
$$

Esse método foi escolhido por resultar em dados mensais, necessitar de poucas variáveis climatológicas e apresentar boa estimativa para regiões de clima úmido.

A remoção das tendências de cada árvore foi feita pela aplicação das funções de ajuste e a divisão de cada uma delas das séries dendrocronológicas. Após obter-se o índice de cada árvore, fez-se a média entre eles obtendo-se, assim, a cronologia local, isto é, a série na qual será feito todo o estudo (Figura 3). 
Figura 3 - Séries de anéis de crescimento de Painel (curvas em preto) e suas tendências (curvas em vermelho). A média dentre as curvas sem a tendência é a cronologia local (curva em azul).

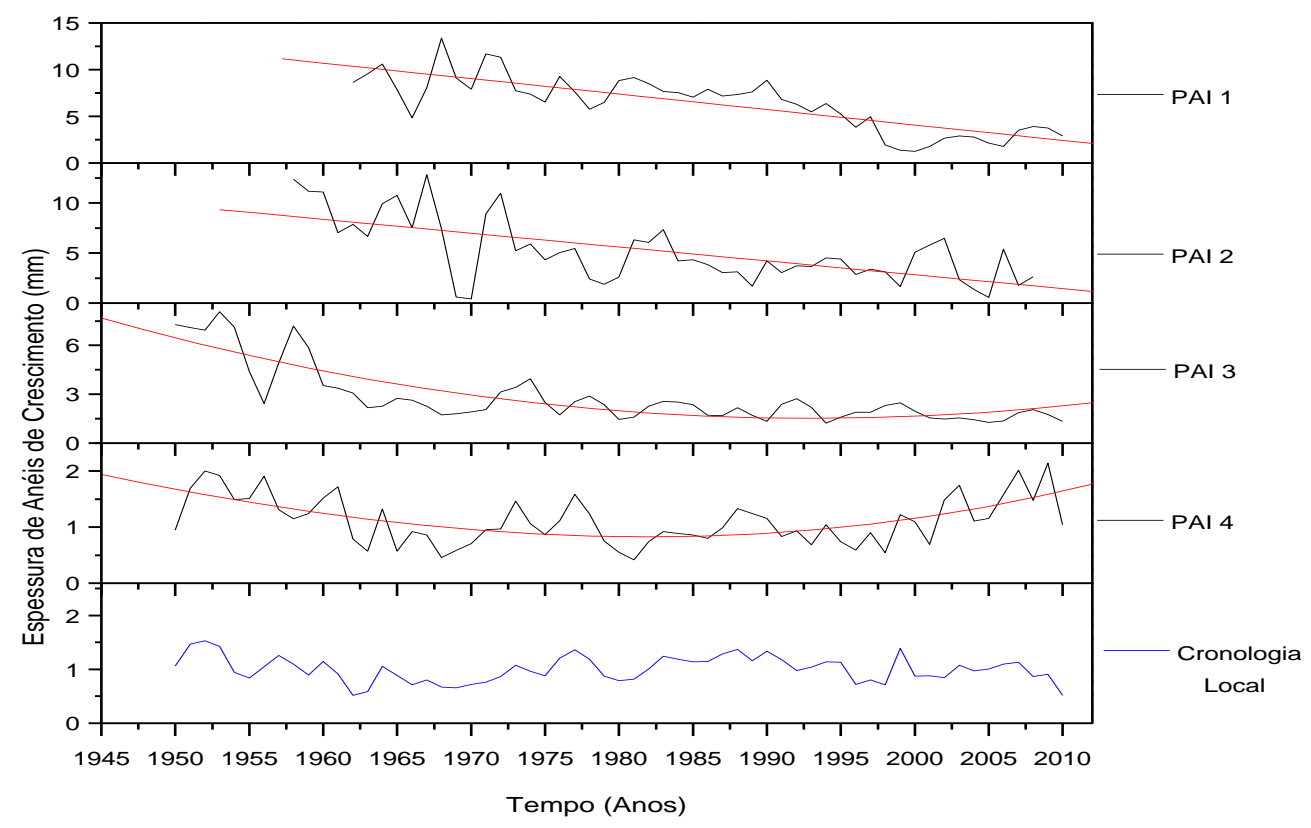

Fonte: Autores.

As correlações entre as variáveis climatológicas temperatura e precipitação média anual e o Índice de anéis de crescimento são mostradas na Figura 4.

Figura 4 - Coeficiente de correlação de Pearson entre as variáveis climatológicas precipitação e temperatura e o índice de anéis de crescimento de árvores de Painel/SC.

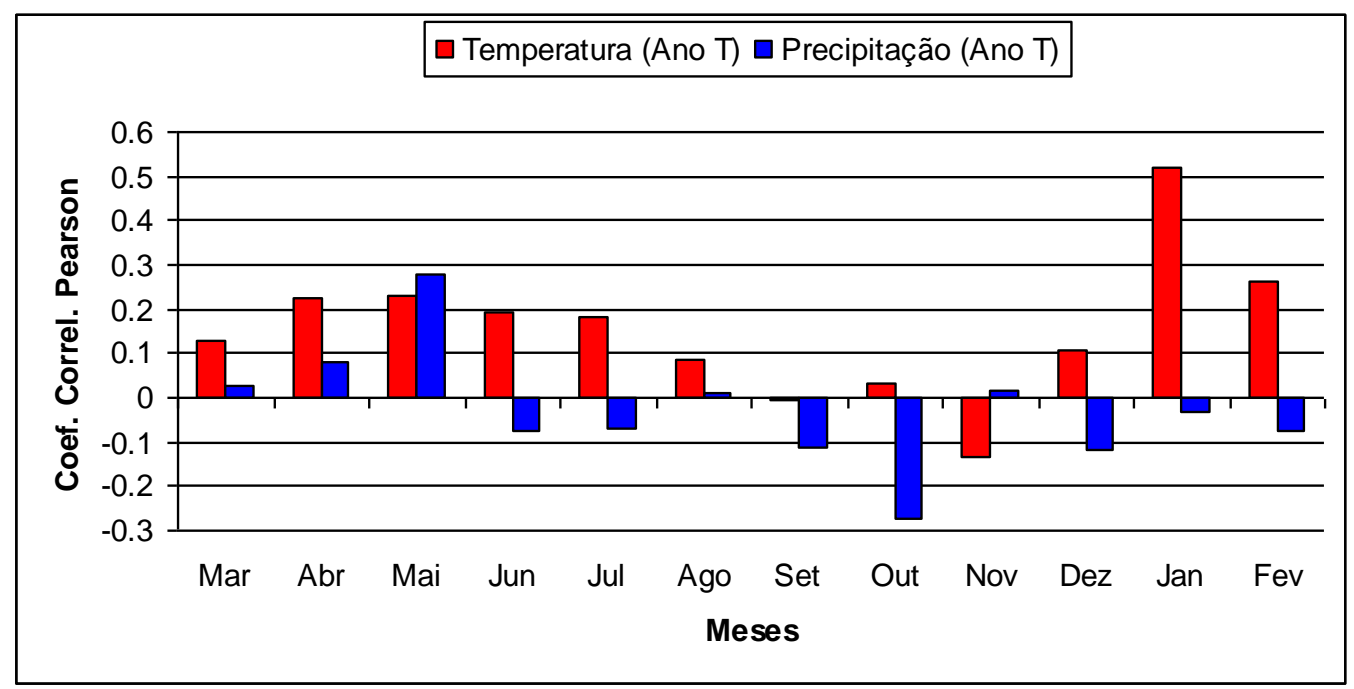

\section{Fonte: Autores.}

$\mathrm{Na}$ avaliação de cada mês, a temperatura mostrou correlação significativa e positiva para os meses de janeiro $(r=0,5206, n=49, p=0,0001258)$ e fevereiro $(r=$ 
$0,26453, n=49, p=0,06624)$.

Para a precipitação, maio apresentou correlação significativa e positiva $(r=$ 0,28097, $n=49, p=0,05051$ ), enquanto que, para o mês de outubro, ocorreu anticorrelação significativa $(r=-0,27267, n=49, p=0,06079)$.

Na investigação sazonal (Figura 5), a correlação com a temperatura do verão $(r=$ 0,42286, $n=49, p=0,00247)$ e do outono $(r=0,24517, n=49, p=0,0895)$ foram significativas e positivas. Para o inverno, a correlação positiva não atingiu o nível significativo.

Para a precipitação, nenhuma das estações do ano apresentou correlação significativa.

Figura 5 - Coeficiente de correlação de Pearson entre a climatologia sazonal e o índice de anéis de crescimento de árvores.

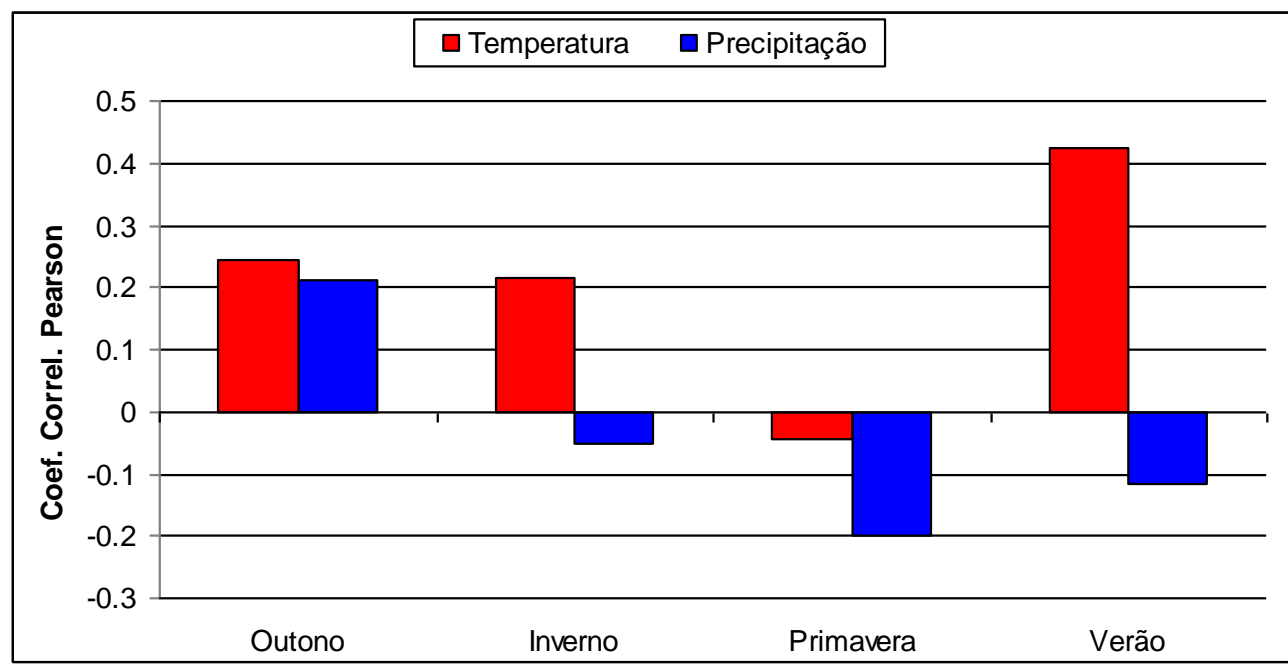

Fonte: Autores.

A correlação dos anéis de crescimento com a série mensal de evapotranspiração, apenas para o mês de janeiro foi significativa $(r=0,3487, n=49, p=0,014)$ (Figura 6).

Figura 6 - Coeficiente de correlação de Pearson entre a evapotranspiração e o índice de anéis de crescimento de árvores.

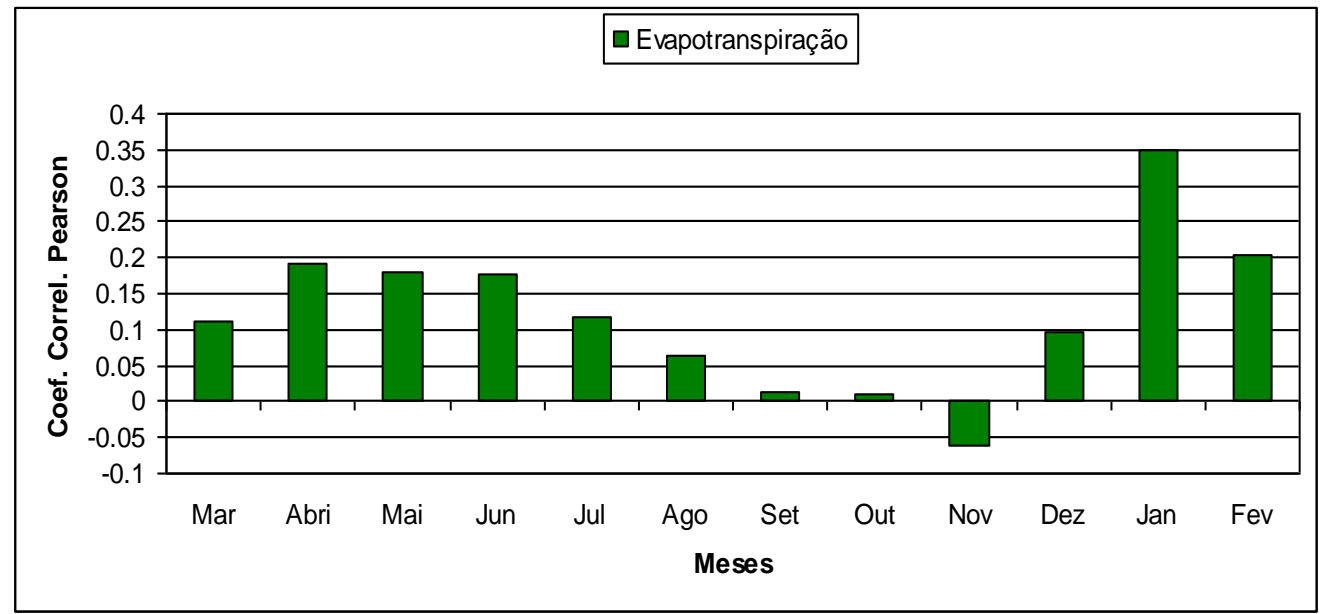

Fonte: Autores. 


\section{DISCUSSÃO}

O comportamento das amostras salienta que as variáveis climatológicas influenciam no crescimento das plantas.

$\mathrm{Na}$ Figura 4, é possível notar que a temperatura se mostrou mais influente que a precipitação entre os meses de dezembro e abril. Apenas os meses de setembro e novembro apresentaram correlações negativas para essa variável.

É notável a influência positiva do clima no crescimento das plantas quando há associação entre as variáveis climatológicas que acarretam em bom condicionamento para o crescimento. Como ocorre no mês de maio (mês menos chuvoso e com temperaturas amenas), que apresentou correlação significativa para a precipitação, enquanto que outubro (mês com maior volume de chuva e temperaturas levemente mais elevadas) houve uma anti-correlação significativa para precipitação.

A precipitação sazonal do local se concentra no verão e na primavera, que juntos somam o maior volume de chuva com $(147,14 \mathrm{~mm})$ e $(147,76 \mathrm{~mm})$, respectivamente. Em seguida, o inverno $(127,7 \mathrm{~mm})$ e o outono $(105,51 \mathrm{~mm})$.

$\mathrm{Na}$ análise sazonal (Figura 5), o outono apresentou correlação positiva com a precipitação e temperatura. Isso pode estar atrelado ao registro de menor índice pluviométrico e temperaturas amenas $\left(13,8^{\circ} \mathrm{C}\right)$. O inverno apresenta boa correlação com a temperatura $\left(10,3^{\circ} \mathrm{C}\right)$ e anti-correlação com a precipitação.

$\mathrm{Na}$ primavera, nenhuma das variáveis correlacionaram bem, o que pode ter relação com o volume de precipitação $(147,14 \mathrm{~mm})$ juntamente as temperaturas mais amenas, em torno de $\left(13,2^{\circ} \mathrm{C}\right)$. Essas condições podem resultar em solo muito úmido, em partes devido à primavera ser, segundo Monteiro (2001), uma estação instável com menos horas de insolação em resposta à nebulosidade trazida pelos complexos convectivos de mesoescala (CCM).

Apesar do desenvolvimento da $\mathrm{A}$. angustifolia estar ligado às baixas temperaturas (SOUSA; AGUIAR, 2012), no verão as temperaturas mais altas $\left(16,8^{\circ} \mathrm{C}\right)$ foram favoráveis ao crescimento porque a estação também apresenta grande volume de chuva.

Para Albiero Junior, (2014), a qualidade do sítio onde as plantas se desenvolveram depende de muitos fatores efetivos e das interações entre eles, onde a umidade do solo é o fator mais relacionado com a qualidade do sítio. Dessa forma, houve uma contribuição em conjunto entre precipitação e temperatura no decorrer do ano, o que fez com que algumas estações apresentassem melhor condição para o crescimento das plantas, mesmo não sendo essas as estações de desenvolvimento cambial, como foi o caso do outono. A condição do solo corrobora com Worbes (1988) que destaca que anéis largos se desenvolvem em solo fértil enquanto que anéis estreitos se formam quando o indivíduo cresce em solo pobre. 
A série de evapotranspiração segue a sazonalidade da temperatura. A primavera e o verão, apesar de serem estações chuvosas, também têm boa insolação (MONTEIRO, 2001), um indicativo de que as chuvas se originam de sistemas sinóticos com curta escala de duração.

No caso das plantas, para determinada condição atmosférica, a resposta a evapotranspiração vai depender da espécie de planta, idade, fase de desenvolvimento etc., bem como da densidade e da composição da comunidade vegetal (VAREJÃOSILVA, 2005).

$\mathrm{Na}$ correlação entre as plantas e a evapotranspiração (Figura 6), as maiores variações ocorrem nos meses da primavera e deve-se ao fato dessa estação apresentar características como grande volume de chuva, temperaturas amenas e pouca insolação. As respostas foram boas para os meses de janeiro e fevereiro, pois há quantidade de umidade e insolação necessárias para que haja evapotranspiração. No outono-inverno, a transferência de vapor d'água para a atmosfera pareceu favorável dentro das condições climáticas dessas estações.

É importante salientar que, segundo Varejão-Silva (2005), muitos fatores ambientais e biológicos são interdependentes, o que pode tornar o estudo da evapotranspiração em superfícies vegetadas bastante complexo.

\section{CONCLUSÃO}

No estudo, ficou clara a influência das variáveis climatológicas no crescimento das plantas, porém essas variáveis atuam de maneira conjunta na tentativa de manter condições adequadas para a vida da planta.

Na investigação mês a mês, maio mostrou melhor condição para o crescimento das árvores. Enquanto que as altas temperaturas de janeiro foram favoráveis e o regime de chuva de outubro desfavorável.

Em situações de grande volume de precipitação acompanhada de temperaturas baixas, há redução no crescimento das árvores e acredita-se que seja por manter o solo com umidade em excesso. No outono, as baixas temperaturas atuam a favor do crescimento porque essa estação acumula baixo volume pluviométrico.

No verão, o efeito positivo das altas temperaturas vem atrelado ao fato de que nessa época do ano ocorrem mais chuvas. A primavera não se mostrou ser uma estação favorável ao crescimento, em parte por apresentar elevado volume de chuva, temperaturas amenas e pouca insolação.

É correto esperar que uma análise feita com mais amostras e para um período maior revele características do local que talvez não foram percebidas pela cronologia aqui desenvolvida. Além de que cronologias maiores possibilitariam a reconstrução de 
perfis climáticos regionais. O fato de observar relação direta entre o desenvolvimento da madeira e o clima operante é um indício de que trabalhos em dendrocronologia para este local podem ser desenvolvidos.

\section{AGRADECIMENTO}

CL agradece a FVE, pela bolsa de doutoramento; e ao IP\&D, pelo suporte técnico durante o desenvolvimento da pesquisa.

\section{REFERÊNCIAS}

ALBIERO JUNIOR, A. Estrutura populacional e dendroecológica de Araucaria angustifolia (Bertol.) Kuntze em diferentes condições de crescimento no Parque Nacional do Iguaçu/PR: Interior e borda de floresta natural. 2014. Dissertação (Mestrado em Botânica) - Universidade Federal do Paraná, 2014.

BRYSON, R. A.; DUTTON, J. A. Some aspects of the variance spectra of tree rings and varves. Annals of the New York Academy of Sciences, v.95, n.1, p. 580-604, 1961.

COELHO, J. V. Dendrocronologia: método matemático para determinação da idade das árvores. 2011.Tese (Doutorado em Física Ambiental) - Universidade Federal do Mato Grosso, Cuiabá, 2011.

ENQUIST, B.J.; LEFFLER, A. J. Long-term tree ring chronologies from sympatric tropical dry-forest trees: individualistic responses to climate variation. Journal of Tropical Ecology, v.17, p. 41-60, 2001.

FICHTLER, E. et al. Climatic signals in tree rings of Burkea Africana and Pterocarpus angolensis from semiarid forest in Namibia. Trees, v.18, p. 422-451, 2004.

FLOWER, A.; SMITH, D. J. A dendroclimatic reconstruction of June-July mean temperature in the northern Canadian Rocky Mountains. Dendrochronologia, v. 29, n. 1 , p. $55-63,2010$.

FRITTS, H.C. Tree rings and climate. London: Academic Press, 1976.

GERHARDT. E. J. et al. Contribuição da análise multivariada na classificação de sítios em povoamentos de Araucaria angustifólia (Bert.) O. Ktze., baseada nos fatores físicos e morfológicos do solo e no conteúdo de nutrientes da serrapilheira. Ciência

Florestal, v. 11, n. 2, p. 41- 57, 2001.

INOUE, M. T.; RODERJAN, C.V.; KUNIYOSHI, Y.S. Projeto madeira do Paraná. Curitiba: FUPEF/UFPR, 1984.

KÖPPEN, W. Climatologia. México: Fundo de Cultura Econômica, 1931.

LINDMANN, C. A. A vegetação no Rio Grande do Sul. Belo Horizonte: EDUSP, 1974. 
MAACK. R. Geografia Física do Estado do Paraná. Curitiba: José Olympio, 1968.

MONTEIRO, M. A. Caracterização climática do estado de Santa Catarina: uma abordagem dos principais sistemas atmosféricos que atuam durante o ano. Geosul, v.16, n.31, p 69-78, 2001.

NASCIMENTO, A. R. T.; LONGHI, S. J.; BRENAS, D. A. Estrutura e padrões de distribuição espacial de espécies arbóreas em uma amostra de floresta ombrófila mista de Nova Prata, RS. Ciência Florestal, v.11, n.1, p.105-119, 2001.

OLIVEIRA, J. M. Anéis de crescimento de Araucaria angustifolia (Bertol) 0. Kuntze: bases de dendroecologia em ecossistemas subtropicais montanos no Brasil. 2007. Tese (Doutorado em Ecologia) - Universidade Federal do Rio Grande do Sul, Porto Alegre, 2007.

PÉLLICO NETTO, S.; SANQUETTA, C. R.; BRENA, D. A. A Floresta de Araucaria e transicoes. In: SEELIGER, U.; CORDAZZO, C.; BARBOSA, F. (Ed.). Os sites e o Programa Brasileiro de Pesquisas Ecológicas de Longa Duração. Belo Horizonte: Universidade Federal de Minas Gerais: FundaÇÃo Universidade Federal do Rio Grande do Sul, 2002. p. 167-184.

RODERJAN, C. V. et al. As unidades fitogeográficas do estado do Paraná, Brasil. Ciência \& Ambiente, n. 24, p. 78-118, 2002.

SANTAROSA, E. et al. Crescimento Sazonal em Araucaria angustifolia: Evidências Anatômicas. Revista Brasileira de Biociências, v. 5, n.1, p.618-620, 2007.

SAVVA, Y. et al. Genetic and environment signals in tree rings from different provenances of Pinus sylvestris L. planted in the southern taiga, central Siberia. Trees, v.16, p.313-324, 2002.

SONEGO, R. C.; BACKES, A.; SOUZA, A. F. Descrição da estrutura de uma Floresta Ombrófila Mista, RS, Brasil, utilizando estimadores não-paramétricos de riqueza e rarefação de amostras. Acta Botanica Brasilica, v. 21, n. 4, p. 943-955, 2007.

SOUSA, V. A.; AGUIAR, A.V. Programa de melhoramento genético de Araucária da Embrapa Florestas: Situação atual e perspectivas. Embrapa Florestas. Colombo, Paraná, 2012. 40 p. (Embrapa florestas. Documentos, 237).

THORNTHWAITE, C. W. An approach toward a rational classification of climate. Geographical Review, v. 38, n.1, p. 55-94, 1948.

TROVATI, L. R.; FERRAZ, E. S. B. Influência da precipitação e da temperatura na densidade dos anéis de crescimento de Pinus oocarpa. IPEF, v.26, p.31-36, 1984.

VAREJÃO-SILVA, M. A. Meteorologia e Climatologia. Recife: Versão Digital, 2005.

WORBES, M. Variety in structure of annual growth zoens in Tabebuia Barbarta (E.Mey) Sandew, Bignoniaceae, a tropical tree from Central Amazonian inundation forests. Dendrochronologia, v. 6, p.71-89, 1988.

ZANZI, A. et al. Spectral analysis on mountain pine tree-ring chronologies.

Dendrochronologia, v. 24, p.145-154, 2007. 